Article

\title{
Direct Phenological Responses but Later Growth Stimulation upon Spring and Summer/Autumn Warming of Prunus spinosa L. in a Common Garden Environment
}

\author{
Kristine Vander Mijnsbrugge ${ }^{1, *} \mathbb{( D}$, Jessa May Malanguis ${ }^{2}\left(\mathbb{D}\right.$, Stefaan Moreels ${ }^{1}$, Arion Turcsán ${ }^{3}$, \\ Nele Van der Schueren ${ }^{1}$ and Eduardo Notivol Paino ${ }^{4}$ (D) \\ 1 Department of Forest Ecology and Management, Research Institute for Nature and Forest, \\ 9500 Geraardsbergen, Belgium; stefaan.moreels@inbo.be (S.M.); vdsnele@hotmail.be (N.V.d.S.) \\ 2 Division of Natural Sciences and Mathematics, University of the Philippines Visayas Tacloban College, \\ Magsaysay Blvd., Tacloban City 6500, Philippines; malanguisjessamay@gmail.com \\ 3 Bavarian State Institute of Forestry, Department Soil and Climate, Hans-Carl-von-Carlowitz-Platz 1, \\ D-85354 Freising, Germany; raup25@gmail.com \\ 4 Department of Forest Resources, Centro de Investigación y Tecnología Agroalimentaria de Aragón (CITA), \\ Avda. Montañana 930, 50059 Zaragoza, Spain; enotivol@cita-aragon.es \\ * Correspondence: kristine.vandermijnsbrugge@inbo.be
}

Citation: Vander Mijnsbrugge, K.; Malanguis, J.M.; Moreels, S.; Turcsán, A.; Van der Schueren, N.; Notivol Paino, E. Direct Phenological Responses but Later Growth Stimulation upon Spring and Summer/Autumn Warming of Prunus spinosa L. in a Common Garden Environment. Forests 2022, 13, 23. https://doi.org/10.3390/ f13010023

Academic Editor: Craig Nitschke

Received: 22 November 2021

Accepted: 20 December 2021

Published: 24 December 2021

Publisher's Note: MDPI stays neutral with regard to jurisdictional claims in published maps and institutional affiliations.

Copyright: (C) 2021 by the authors. Licensee MDPI, Basel, Switzerland. This article is an open access article distributed under the terms and conditions of the Creative Commons Attribution (CC BY) license (https:// creativecommons.org/licenses/by/ $4.0 /)$.

\begin{abstract}
Future predictions of forest ecosystem responses are a challenge, as global temperatures will further rise in the coming decades at an unprecedented rate. The effect of elevated temperature on growth performance and phenology of three Prunus spinosa L. provenances (originating from Belgium, Spain, and Sweden) in a common garden environment was investigated. One-year-old seedlings were grown in greenhouse conditions and exposed to ambient and elevated temperatures in the spring (on average $5.6^{\circ} \mathrm{C}$ difference) and in the late summer/autumn of 2018 (on average $1.9^{\circ} \mathrm{C}$ difference), while they were kept hydrated, in a factorial design. In the following years, all plants experienced the same growing conditions. Bud burst, leaf senescence, height, and diameter growth were recorded. Height and radial growth were not affected in the year of the treatments (2018) but were enhanced the year after (2019), whereas phenological responses depended on the temperature treatments in the year of the treatments (2018) with little carry-over effects in the succeeding years. Spring warming enhanced more height growth in the succeeding year, whereas summer/autumn warming stimulated more radial growth. Spring warming advanced bud burst and shortened the leaf opening process whereas summer/autumn warming delayed leaf senescence and enlarged the duration of this phenophase. These results can help predict the putative shifts in species composition of future forests and woody landscape elements.
\end{abstract}

Keywords: climate change; elevated temperature; bud burst; leaf senescence; cumulative logistic regression; black thorn; provenance trial; local adaptation

\section{Introduction}

Temperature is one of the fundamental drivers of ecological processes in forests [1]. It is critical to understand how tree species will respond to the predicted higher global temperatures. A well-studied direct effect of experimental warming in boreal and temperate tree species is the prolongation of the growing season with buds flushing earlier and leaves senescing later [2-4]. Although many experimental studies focus on the seedling and sapling stage of tree species, this effect can also be seen in mature trees [5]. Analysis of the Pan European Phenology (PEP) network data (1951-2013) corroborated the extension of the growing season due to global warming but also indicated limits to this extension [6]. A longer growing season will affect the competitive ability and survival of tree species by increasing their vulnerability to late spring frosts, to early autumn frosts, to longer and more severe drought periods, and to certain phytopathogens $[7,8]$. 
Rising temperature is generally thought to facilitate carbon allocation to internal growth processes in trees [9]. Still, it remains difficult to predict the order of magnitude of growth changes upon warming as different species respond differently to warming and heat stress [9]. In addition, tree species have a broad range for the optimum temperature for photosynthesis and this may vary between provenances from different thermal origins $[10,11]$. Furthermore, seedlings of species from temperate and boreal forests are, to a certain extent, able to acclimatize to the photosynthetic temperature optima in response to experimental warming [12,13].

Stimulation, no change or retardation in growth can result from warming. In seedlings from three of four coniferous species, growth was enhanced upon warming and was correlated with higher net photosynthetic rate, chlorophyll content, and leaf area in comparison to the control group. The growth of the fourth coniferous species was not influenced by elevated temperature [14]. Two-year warming of seedlings did not affect biomass in Quercus variabilis Blume or Pinus densiflora Siebold and Zucc. [15]. Higher growth temperature reduced the net photosynthesis, increased respiration, and reduced height, diameter and biomass production in Quercus rubra L. seedlings [16]. Finally, results from a three-year warming of juvenile trees from 11 boreal and temperate tree species suggested that species growing nearest their warm range limit exhibited reductions in net photosynthesis and growth, whereas species near their cold range limit responded positively to warming [17].

The shrub Prunus spinosa L. (Black thorn) is common in European deciduous forests, hedges, and thickets and in open farmland [18]. It is an insect pollinated and bird dispersed species [19]. In old farm hedges and wooded banks, it is considered to be autochthonous as these shrubs used to be planted with locally sourced material. Nowadays, P. spinosa is planted in forests and agricultural land to improve species diversity, restore historical landscapes, and preserve wildlife habitat. Studies on the growth and phenology of $P$. spinosa are limited. In a provenance trial in Belgium, two southern European provenances tended to flush and flower earlier compared to several Belgian provenances, and one of these two provenances also displayed lesser height growth compared to the Belgian provenances [20]. Phenophases of P. spinosa were analyzed in two plantations in Belgium containing clonal replicates of different genotypes derived from several natural populations [21]. Variance partitioning analysis revealed that timing of bud burst and leaf fall displayed a relatively high genetic control in the clone plantations, likely caused by local adaptation. Likewise, variations in the timing of bud burst between the two clonal plantations were correlated to different local climates of the two plantations, indicating a plastic spring temperature response. A two-year study on 16 P. spinosa shrubs growing in situ in Romania provided a similar outcome with earlier timing of bud burst correlated with increased spring temperature [22].

We conducted a common garden experiment with $P$. spinosa originating from three locations in Europe along a latitudinal gradient. Common garden experiments have the advantage of highlighting differences due to genetic factors among provenances grown together in the same environment. We tested whether temperature elevation in the spring and/or in the summer/autumn influenced the growth and phenological responses, and if so, at which time point and to what extent. Lastly, we also verified if a common garden setting was able to detect differences in growth and phenology among the three examined provenances.

\section{Materials and Methods}

\subsection{Seed Collection and Germination}

Berries from P. spinosa were collected in 2016 from three natural populations, from now on called provenances, in Belgium (northern part, Atlantic climate), in Spain (Pyrenees, Alpine climate), and in the south of Sweden (Atlantic climate) (Table 1). Berries were picked from 39 shrubs (Table 1). As P. spinosa is able to form clonal root suckers, care was taken to pick from individuals that were several meters apart from each other and looked morphologically different. The climate and day length at the origin of the provenances is shown in Figure 1 (mean monthly maximum and minimum temperature and mean 
monthly precipitation for 1970-2000, data extracted from WorldClim version 2 [23] and NOAA Solar Calculator [24]).

Table 1. Description of the sampling sites and details on the seedlings of P. spinosa L. in the common garden. Abb.: provenance abbreviation; $\mathrm{n}^{\circ}{ }_{\mathrm{mpl}}$ : number of mother plants; $\mathrm{n}^{\circ}$ : number of seedlings; $\mathrm{n}^{\circ} \mathrm{t} \mathrm{Cc} / \mathrm{cw} / \mathrm{wc} / \mathrm{ww}$ : number of seedlings according to the temperature treatments in the spring (first letter) and in the summer/autumn (last letter) of 2018 with cc: cold-cold, cw: cold-warm, wc: warm-cold, and ww: warm-warm.

\begin{tabular}{|c|c|c|c|c|c|c|c|}
\hline $\begin{array}{l}\text { Country, } \\
\text { Region, } \\
\text { Village }\end{array}$ & Abb. & Latitude & Longitude & $\begin{array}{l}\text { Altitude } \\
\text { (m a.s.1.) }\end{array}$ & $\mathrm{n}_{\mathrm{mpl}}^{\circ}$ & $\mathbf{n}^{\circ}$ & $\begin{array}{c}\mathbf{n}_{t}^{\circ} \\
\mathrm{cc} / \mathrm{cw} / \mathrm{wc} / \mathrm{ww}\end{array}$ \\
\hline $\begin{array}{c}\text { Belgium, } \\
\text { Flanders, } \\
\text { Kriephoek } \\
\text { Snain }\end{array}$ & $\mathrm{Be}$ & 50.953324 & 3.663467 & 10 & 15 & 109 & $33 / 23 / 23 / 30$ \\
\hline $\begin{array}{c}\text { Pyrenees, } \\
\text { Linas De } \\
\text { Broto }\end{array}$ & $\mathrm{Sp}$ & 42.630049 & -0.169068 & 1270 & 11 & 79 & $24 / 18 / 14 / 23$ \\
\hline $\begin{array}{c}\text { Sweden, } \\
\text { Skane, Dalby }\end{array}$ & Sw & 55.67668 & 13.32481 & 58 & 13 & 95 & $30 / 21 / 16 / 28$ \\
\hline
\end{tabular}

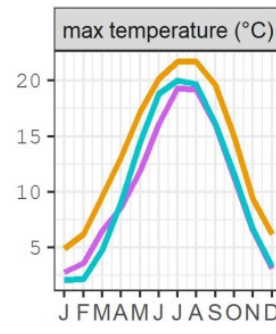

(a)

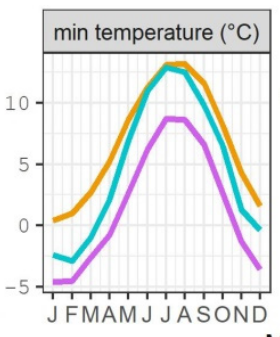

(b)

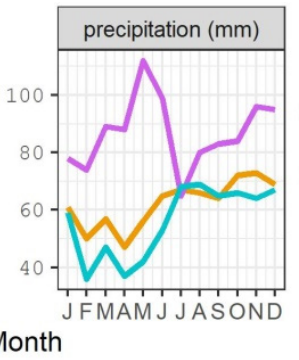

(c)

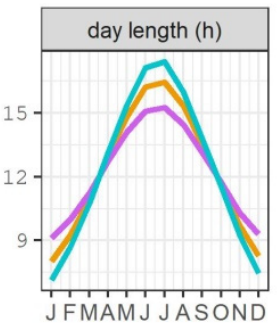

(d)

Figure 1. Climate and day length at the origin of the provenances of P. spinosa L. (a) Mean monthly maximum temperature; (b) mean monthly minimum temperature; (c) mean monthly precipitation; (d) day length.

Seeds were cleaned and mingled with standard nursery potting soil $(20 \%$ organic matter, $\mathrm{pH} 5.0-6.5$, EC $450 \mu \mathrm{S} / \mathrm{cm}$, dry matter $25 \%, 1.5 \mathrm{~kg} / \mathrm{m}^{3}$ powdered compound fertilizer NPK $12+14+24$ ) at the nursery of the Research Institute of Nature and Forest in Geraardsbergen, Belgium. Seeds germinated in 2017 and up to 8 seedlings for each mother tree were included in the common garden experiment (in total: 109 seedlings for Belgium, 79 seedlings for Spain, and 95 seedlings for Sweden, Table 1). The seedlings were watered to full capacity twice a week. They were then transferred to forestry propagation trays and were tended in a greenhouse without side walls. Seedlings were protected from strong insolation by an automatically regulated grey shade net.

\subsection{Temperature Treatments in 2018 and Measurements/Observations}

Seedlings from each mother plant were randomly allocated to two groups at the end of 2017. For each group, the seedlings were randomly intermingled in the propagation trays (completely randomized design). On 20 February 2018, the two groups of seedlings were transferred to two greenhouse chambers with different temperature regimes (Figure 2a). One chamber was heated while the other was not (on average $5.6^{\circ} \mathrm{C}$ difference). The seedlings were watered to full capacity twice a week to keep them well hydrated. Seedlings were retained here until leaves were unfolded for all plants, which happened on 10 April 2018. After this first temperature treatment, all trays were placed together in a standard greenhouse, 
randomly intermingled and all seedlings were cut back at $15 \mathrm{~cm}$ height. The plants stayed here until the end of July 2018.

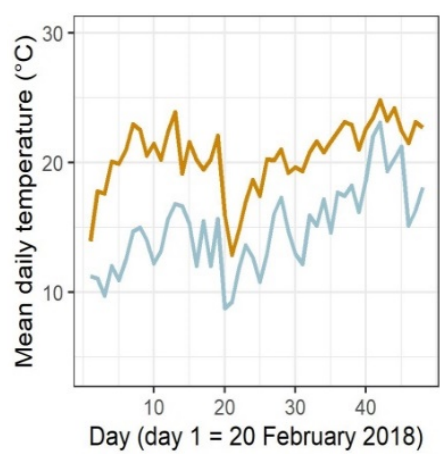

(a)

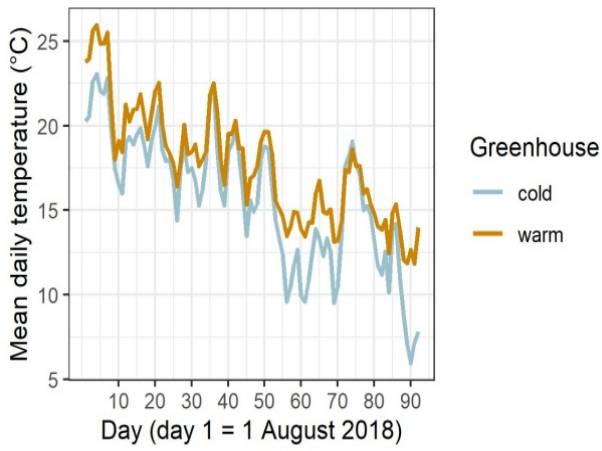

(b)

Figure 2. Mean daily temperatures in the two greenhouse chambers in spring (a) and in the two greenhouses in summer/autumn (b) in 2018.

On the 1st of August 2018, the seedlings were again divided into two new groups. Half of the plants from the warm spring condition were placed into the first group and the other half in the other group, and the same was performed for the cold spring condition group (factorial design). For the second temperature treatment, one new group remained in the standard greenhouse whereas the other group was placed in the greenhouse without walls. The two conditions differed on average $1.9^{\circ} \mathrm{C}$ from August until October (Figure 2b). In both greenhouses, an automatic grey shade net operated in the same way, to protect seedlings from harmful insolation. At the beginning of November, all trays were placed together, intermingled, in the greenhouse without walls.

In December 2018, the plants were moved to 1-litre pots using standard nursery potting soil (20\% organic matter, pH 5.0-6.5, EC $450 \mu \mathrm{S} / \mathrm{cm}$, dry matter $25 \%, 1.5 \mathrm{~kg} / \mathrm{m}^{3}$ powdered compound fertilizer NPK $12+14+24)$. No fertilizer was added. The pots were positioned on a container field with an automatic watering system at the Research Institute for Agriculture, Fisheries and Food, in Melle, Belgium. The automatic system applied water to the plants every two days with rotating sprinklers, ensuring full coverage. All plants were once more intermingled. In January 2020 all plants were transferred to 4-litre pots using standard nursery potting soil (20\% organic matter, pH 5.0-6.5, EC $450 \mu \mathrm{S} / \mathrm{cm}$, dry matter $25 \%, 1.5 \mathrm{~kg} / \mathrm{m}^{3}$ powdered compound fertilizer NPK $\left.12+14+24\right)$. No fertilizer was added. All plants were anew intermingled and stayed on the container field in 2020.

Plant height and stem diameter $1 \mathrm{~cm}$ above soil level were measured in the winters of 2017, 2018, 2019, and 2020.

Bud burst was scored at regular intervals in the spring of 2018, 2019, and 2020 (Table 2), following a 5 level protocol (1: buds in winter rest, 2: buds swelling, 3: first green leaves protruding, but still folded, 4: leaves unfolding, 5: leaves unfolded) [2]. Leaf senescence was scored in the autumn of 2018, 2019, and 2020 (Table 2) according to a 5 level protocol (1: green leaves, 2: light green leaves, 3: yellowing leaves, 4: leaves turning brown, 5: brown leaves, starting to fall off) [2].

Table 2. Observation dates of the phenophases bud burst and leaf senescence.

\begin{tabular}{ccc}
\hline Year & Bud Burst & Leaf Senescence \\
\hline \multirow{2}{*}{2018} & $26 / 2,1 / 3,5 / 3,8 / 3,12 / 3$, & $26 / 9,16 / 10$ \\
2019 & $15 / 3,19 / 3,26 / 3,3 / 4,9 / 4$ & $12 / 9,15 / 10,9 / 11$ \\
2020 & $18 / 3,29 / 3,5 / 4,10 / 4$ & $14 / 9,2 / 10,23 / 10$ \\
\hline
\end{tabular}


The chlorophyll content of a plant organ is an indicator of the rate of photosynthesis. The relative leaf chlorophyll content was measured on all plants on 23 August 2018 in a non-destructive way with a chlorophyll content meter (CCM-200, Edaphic Scientific, Melbourne, Australia). This instrument measures the optical absorbance of leaf samples in two different wavebands: $653 \mathrm{~nm}$ (chlorophyll) and $931 \mathrm{~nm}$ (near infra-red). The relative chlorophyll content is the ratio of optical transmission at $931 \mathrm{~nm}$ to optical transmission at $653 \mathrm{~nm}$ [25]. Measurements were conducted on the first fully developed and damage-free leaf at the top shoot of the plants.

\subsection{Statistical Analysis}

Linear and generalized linear mixed models were built in the open-source software $\mathrm{R}$ version 3.6.1 [26]. We looked at the responses of the plants (growth, phenology, and relative chlorophyll content) to the temperature treatments in 2018 (T). For the bud burst in 2018, the treatment in the greenhouse chambers (in the fixed part of the models) consisted of only two conditions ("cold" and "warm"). For all other response variables from 2018 onwards, the temperature treatments in 2018 (fixed part) included four conditions: cold in spring and cold in summer/autumn ("cold-cold"), cold in spring and warm in summer/autumn ("cold-warm"), warm in spring and cold in summer/autumn ("warm-cold") and warm in both spring, and summer/autumn ("warm-warm"). "Cold-cold" was the standard treatment to which the others were compared. The provenance (P: three provenances) was added to the fixed part of the models with "Belgium" as the standard provenance to which "Spain" and "Sweden" were compared.

As plants were scored at different dates, the day of observation (D) was added in the fixed part of the phenological models. The height of the plants was also included in the fixed part with $\mathrm{H}_{1}$ as the height at the end of 2017 until $\mathrm{H}_{4}$ as the height at the end of 2020 . For the bud burst and the leaf senescence in 2018, an interaction term between treatment and day was included in the models to account for the different time spans that the plants in the two temperature conditions needed to go through the whole phenophase.

A unique code for each mother plant was present in the random part of the models and, if needed, an individual plant identity was added here to account for different observations on the same plants.

Plant height, stem diameter, and relative chlorophyll content were modeled using linear mixed models in the package lme4 [27].

Plant height and stem diameter $\left(\mathrm{H}_{1}\right.$ and $\left.\mathrm{D}_{1}\right)$ at the end of the first growing season, before the temperature treatments (2017):

$$
\begin{aligned}
& \mathrm{H}_{1}=\alpha_{\mathrm{H} 1}+\beta_{\mathrm{PH} 1} \mathrm{P} \\
& \mathrm{D}_{1}=\alpha_{\mathrm{D} 1}+\beta_{\mathrm{PD} 1} \mathrm{P}
\end{aligned}
$$

The growth increments of both plant height and stem diameter at the end of $2018\left(\mathrm{Hi}_{2}\right.$ and $\left.\mathrm{Di}_{2}\right)$ :

$$
\begin{aligned}
& \mathrm{Hi}_{2}=\alpha_{\mathrm{Hi} 2}+\beta_{\mathrm{PHi} 2} \mathrm{P}+\beta_{\mathrm{THi} 2} \mathrm{~T}+\beta_{\mathrm{H} 1 \mathrm{Hi} 2} \mathrm{H}_{1} \\
& \mathrm{Di}_{2}=\alpha_{\mathrm{Di} 2}+\beta_{\mathrm{PDi} 2} \mathrm{P}+\beta_{\mathrm{TDi} 2} \mathrm{~T}+\beta_{\mathrm{H} 1 \mathrm{Di} 2} \mathrm{H}_{1}
\end{aligned}
$$

The growth increments of plant height and stem diameter at the end of 2019 and 2020 followed the same structure as the increment models of 2018, with starting height $\mathrm{H}_{2}$ and $\mathrm{H}_{3}$, respectively, instead of $\mathrm{H}_{1}$.

Model for the relative leaf chlorophyll content on the 23rd of August 2018 (C):

$$
\mathrm{C}=\alpha_{\mathrm{C}}+\beta_{\mathrm{PC}} \mathrm{P}+\beta_{\mathrm{TC}} \mathrm{T}+\beta_{\mathrm{H} 2 \mathrm{C}} \mathrm{H}_{2}
$$

As the phenological scores were an ordinal data type (natural ordered levels with unknown distances between the levels), models were built with cumulative logistic regression in the $\mathrm{R}$ package ordinal [28]. The function "clmm" fits cumulative link mixed models. The cumulative 
probability $(\mathrm{p})$ of the $\mathrm{i}^{\text {th }}$ phenological score being the $\mathrm{j}^{\text {th }}$ level of the phenological response variable or a level below the $\mathrm{j}^{\text {th }}$ level is modeled. Thus, the cumulative probability is the chance to maximally reach a given level of the phenological variable. The bud burst scores were ordered in reverse, from the end of the process until the beginning: from unfolded leaves to buds in winter rest (from 5 to 1 ) whereas for leaf senescence the scores were ordered in a normal chronological way, from green leaves to brown leaves that are falling off (from 1 to 5). Bud burst scores were reversed for an easier interpretation of the modeled probabilities. A probability of having reached maximally, e.g., a score of 3 in a bud burst response variable that is ordered from 5 to 1 means the chance of reaching a score of 5, 4, or 3 . Therefore, a plant with an early bud burst (higher score at a given time) has a higher modeled probability of having reached a score of 5,4 , or 3 .

Bud burst in 2018:

$$
\log \left(\mathrm{p}_{1} /\left(1-\mathrm{p}_{1}\right)\right)=\alpha_{\mathrm{Trp} 1}-\beta_{\mathrm{Pp} 1} \mathrm{P}-\beta_{\mathrm{Dp} 1} \mathrm{D}-\beta_{\mathrm{Tp} 1} \mathrm{~T}-\beta_{\mathrm{DTp} 1} \mathrm{DT}-\beta_{\mathrm{H} 1 \mathrm{p} 1} \mathrm{H}_{1}
$$

With $\alpha_{\operatorname{Trp} 1}$ as an estimated threshold value for the passing on from one level of the ordinal bud burst variable to the next. A significant interaction term between the day of observation and the temperature treatment indicated that the duration of the bud burst process differed between the warm and the cold condition.

Leaf senescence in 2018 had the same model structure as bud burst in 2018, but with replacement of plant height at the end of $2017\left(\mathrm{H}_{1}\right)$ by the plant height at the end of 2018 $\left(\mathrm{H}_{2}\right)$. Furthermore, the treatment variable (T) now consisted of four conditions instead of two ("cold-cold", "cold-warm", "warm-cold", and "warm-warm").

Bud burst in 2019:

$$
\log \left(\mathrm{p}_{2} /\left(1-\mathrm{p}_{2}\right)\right)=\alpha_{\mathrm{Trp} 2}-\beta_{\mathrm{Pp} 2} \mathrm{P}-\beta_{\mathrm{Dp} 2} \mathrm{D}-\beta_{\mathrm{Tp} 2} \mathrm{~T}-\beta_{\mathrm{H} 2 \mathrm{p} 2} \mathrm{H}_{2}
$$

Leaf senescence in 2019 and bud burst in 2020 had the same model structure as bud burst in 2019, but with replacement of the plant height at the end of $2018\left(\mathrm{H}_{2}\right)$ by the plant height at the end of $2019\left(\mathrm{H}_{3}\right)$. Leaf senescence in 2020 had also the same model structure, but with plant height at the end of $2020\left(\mathrm{H}_{4}\right)$.

\section{Results}

\subsection{Growth Responses to the Temperature Treatments}

After the first growing season of 2017 and before the temperature treatments of 2018, there was already a difference in growth patterns between the three provenances. Both the Spanish and the Swedish provenance were smaller ( $p$-value $<0.001$ and $=0.001$ respectively in Table S1) and had a smaller diameter ( $p$-value $=0.015$ and $<0.001$, respectively, in Table S1) than the Belgian provenance (Figure S1a,b).

In 2018, the height increment was lower for the Spanish and the Swedish provenances ( $p$-value $=0.032$ and $=0.035$ respectively in Table S2, Figure S2), whereas the diameter increment was lower only for the Swedish provenance ( $p$-value $=0.027$ in Table S2, Figure S2). The two temperature treatments in the spring and in the summer/autumn had no significant effect on the height and diameter increment of the plants in this year (no significant treatments for the year 2018 in Table S2). Height and diameter increments in 2019 were smaller for the Swedish provenance $(p$-value $=0.012$ and $=0.031$, respectively, in Table S2, Figure S2). In this year, the temperature treatments of the year before had a significant effect on the increment growths (Figure 3a,b). Both the "warm-cold" and the "warm-warm" conditions resulted in a bigger height increment ( $p$-value $=0.023$ and $=0.002$ respectively in Table S2), whereas the "cold-warm" and the "warm-warm" conditions led to a bigger diameter increment ( $p$-value $=0.004$ and $<0.001$, respectively, in Table S2). In 2020, the temperature treatments did not affect the height increment nor the diameter increment of the plants any further (no significant treatments for 2020 in Table S2). In this last year, height increment was again lower for both the Spanish and the Swedish provenance in comparison to the Belgian provenance ( $p$-value $<0.001$ for both provenances in Table S2, Figure S2) 
whereas diameter increment was lower only for the Swedish provenance $(p$-value $=0.001$ in Table S2, Figure S2).

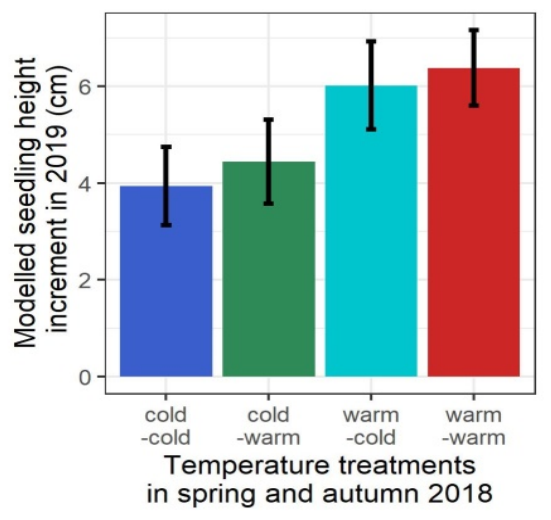

(a)

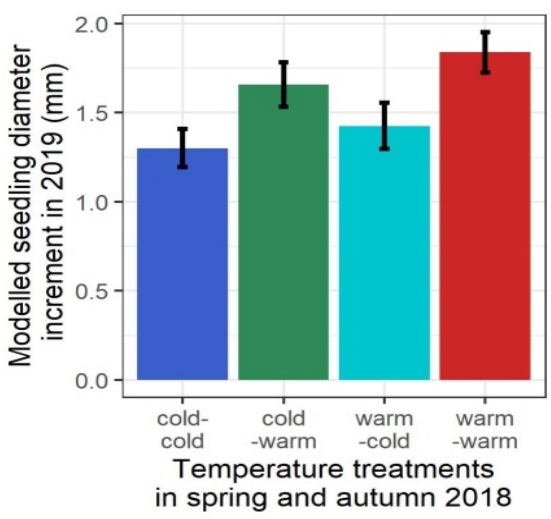

(b)

Figure 3. Bart chart of the modeled height increment (a) and diameter increment (b) for the Belgian provenance in 2019, with standard error, according to the temperature treatments in 2018.

\subsection{Phenological Responses to the Temperature Treatments}

In the spring of 2018, the first temperature treatment was conducted with two conditions: warm and cold. Bud burst started earlier in the warm condition ( $p$-value $<0.001$ in Table S3, Figure $4 \mathrm{a}$ ), and the duration of the process was shorter in this chamber ( $p$-value $<0.001$ for the interaction between day and treatment in Table S3, a steeper slope for the "warm" condition in Figure 4a). Bud burst started later for the Spanish and the Swedish provenance compared to the Belgian provenance ( $p$-value $=0.027$ and $<0.001$, respectively, in Table S3, Figure $4 \mathrm{~b}$ ) and it started earlier for smaller plants ( $p$-value $<0.001$ in Table S3, Figure $4 c$ ).

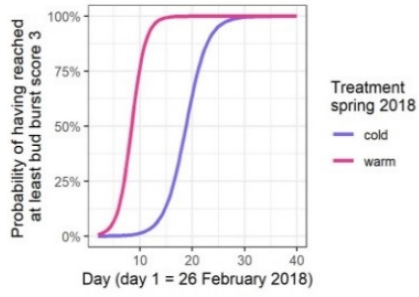

(a)

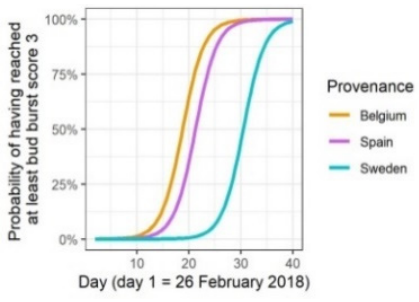

(b)

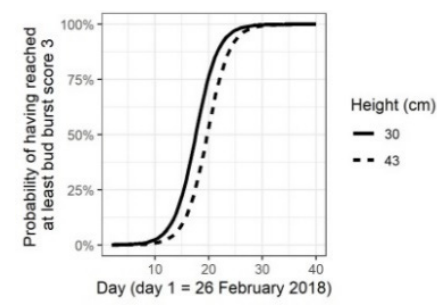

(c)

Figure 4. Modeled probability of having reached at least a given bud burst score in the spring temperature treatment in the greenhouse chambers in 2018, depending on the treatment (model fit shown for the Belgian provenance and for the average plant height) (a), depending on the provenance (for the "cold" treatment and for the average plant height) (b), and depending on the height of the plants (for the Belgian provenance and for the "cold" treatment) (c).

Leaf senescence during the summer/autumn temperature treatment in 2018 occurred later in the plants of the "cold-warm", "warm-cold" and "warm-warm" conditions compared to the "cold-cold" condition ( $p$-value $=0.007,0.001$ and 0.001 respectively in Table S4, Figure 5a). The "warm-cold" treatment shortened the duration of the senescence process than the "coldcold" condition (steeper slope for "warm-cold" condition in Figure 5a, $p$-value $=0.011$ for the interaction term between this condition and day in Table S4), whereas the "cold-warm" and "warm-warm" conditions were characterized by a longer duration of the senescence phenophase (less steep slopes for these conditions compared to "cold-cold" in Figure 5a, $p$-value $=0.005$ and 0.008 for "cold-warm" and "warm-warm", respectively, in interaction with day in Table S4). The Swedish provenance entered leaf senescence earlier than the Belgian provenance ( $p$-value $<0.001$ in Table S4, Figure 5b). Finally, smaller plants displayed a later leaf senescence ( $p$-value $<0.001$ in Table S4, Figure 5c). Results on the timing of the leaf senescence in the different treatment con- 
ditions were corroborated by a relative chlorophyll content measurement on the 23rd of August 2018, with higher values for "cold-warm", "warm-cold" and "warm-warm" ( $p$-value < 0.001 for the three conditions in Table S5, Figure 6) corresponding to a later timing of the leaf senescence as observed by the visual leaf decoloration scoring later on.

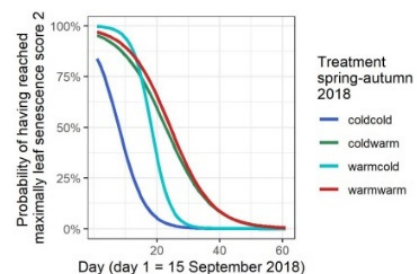

(a)

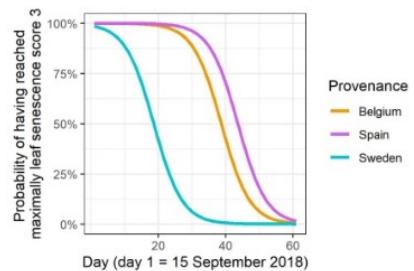

(b)

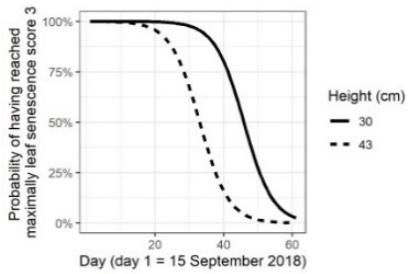

(c)

Figure 5. Modeled probability of having reached maximally a given leaf senescence score in the summer/autumn temperature treatment in 2018, depending on the treatment (for the Belgian provenance and for the average plant height) (a), depending on the provenance (for $\mathrm{T}_{\text {cold-cold }}$ and for the average plant height) (b), and depending on the height of the plants (for the Belgian provenance and for $\left.\mathrm{T}_{\text {cold-cold }}\right)(\mathrm{c})$.

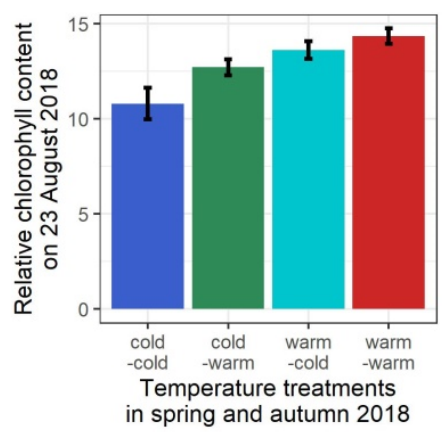

Figure 6. Bar chart of modeled relative chlorophyll content for the Belgian provenance on 23 August 2018, with standard error, according to the temperature treatments in 2018.

Temperature treatments in the preceding growing season showed only a minor legacy in the timing of bud burst of 2019. The "cold-warm" treatment displayed a later bud burst ( $p$-value $=0.008$ in Table S6, Figure 7a). No effect of the treatments on the leaf senescence in this year was detected anymore (Table S6). When looking at the differences between the provenances, the Swedish provenance, but not the Spanish one, did affect the phenophases in 2019 with a later bud burst and an earlier leaf senescence ( $p$-value $<0.001$ for both phenophases in Table S6, Figure 7b,c).

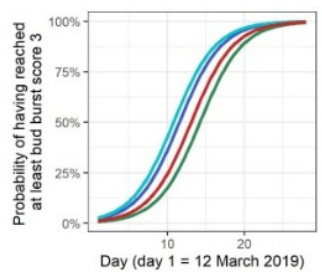

(a)

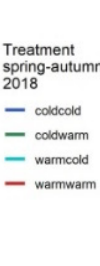

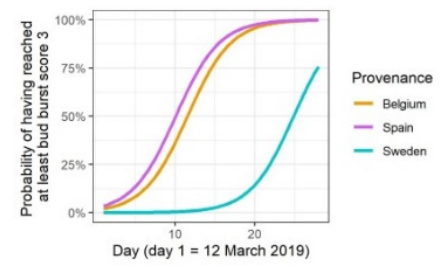

(b)

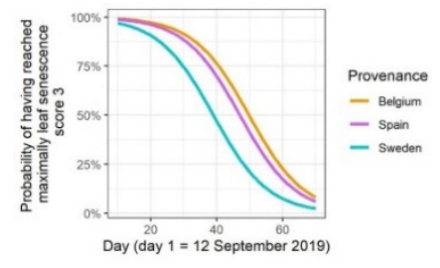

(c)

Figure 7. Modeled probabilities of having reached at least a given bud burst score or having reached maximally a given leaf senescence score in 2019. (a) Model fit for bud burst depending on the temperature treatments in 2018 (for the Belgian provenance and for an average plant height); (b) model fit for bud burst depending on the provenances ("cold-cold" as treatment and for an average plant height); (c) model fit for leaf senescence depending on the provenances ("cold-cold" as treatment and for an average plant height). 
The Spanish and the Swedish provenance both displayed a later timing of the bud burst than the Belgian provenance in 2020 ( $p$-value $=0.002$ and $<0.001$, respectively, in Table S7, Figure 8a), whereas, at the end of the growing season, no effect of the provenances was visible in the leaf senescence (Table S7). In this year, no effect of the temperature treatments in 2018 was still present in the spring phenophase (Table S7), whereas the "cold-warm" condition delayed slightly the leaf senescence ( $p$-value $=0.013$ in Table S7, Figure 8b).

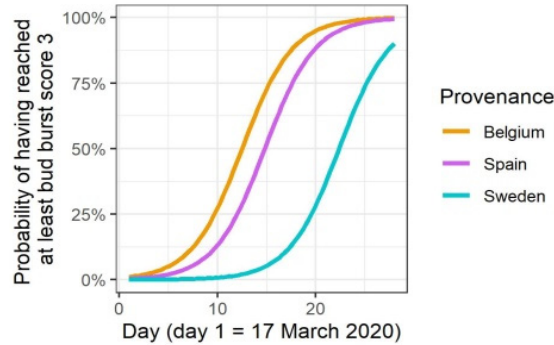

(a)

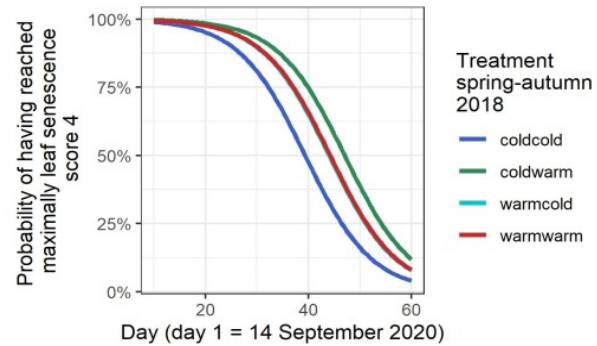

(b)

Figure 8. Modeled probabilities of having reached at least a given bud burst score or having reached maximally a given leaf senescence score in 2020. (a) Model fit for bud burst according to the provenances ("cold-cold" as treatment and for an average plant height); (b) model fit for leaf senescence according to the temperature treatments in 2018 (for the Belgian provenance and for an average plant height).

\section{Discussion}

Our key finding is that the growth responses of $P$. spinosa seedlings upon two temperature treatments, one in the spring and one in the summer/autumn, were only detectable one year after treatments were applied. Moreover, we observed that spring warming enhanced more height growth in the following year, whereas summer/autumn warming enhanced more radial growth in the following year. The Belgian provenance displayed a faster growth than the Swedish (originating from a higher latitude) and the Spanish provenance (originating from a lower latitude but a higher elevation). We recorded a similar timing of bud burst and leaf senescence for seedlings originating from Belgium and Spain, while seedlings from Sweden showed a later bud burst and earlier leaf senescence.

\subsection{Timing and Variability in the Responses to Spring and Summer/Autumn Warming}

It is well-known that the size of a leading shoot of a deciduous tree is mainly determined by the quantity of reserve materials accumulated during the previous year [29]. Accumulation of starch upon the change in growing conditions, as a "carbon saving strategy", is suggested to act as a storage of energy needed for the "recovery phase" when environmental conditions return to normal [30]. The two temperature treatments in 2018 in our experiment only affected the growth of the seedlings one year after the treatments. An elevated photosynthetic activity due to the higher temperatures in our experiment may have induced an accumulation of starch stores in the plants which were consumed in the following year, leading to the observed enhanced growth in this year solely. Our results also suggest that spring warming ("warm-cold" and "warm-warm") enhanced more height growth in the following year, whereas summer/autumn warming ("cold-warm" and "warm-warm") enhanced more radial growth in the following year. A putative explanation can be found in the temporal nonstructural carbohydrate dynamics in trees [31]. We hypothesized that in our experiment, the warming in spring could have enhanced the build-up of nonstructural carbohydrate storage pools in branches, which may have been exploited at the beginning of the next growing season, leading to better height growth. Although it could be expected that a warmer summer/autumn in our experiment, with a higher chlorophyll content in the leaves and a delayed leaf senescence, could directly lead to a prolonged radial growth, we observed an effect on the diameter growth only 
one year later. It is likely that the summer/autumn warming in our experiment may have contributed to a larger storage pool of nonstructural carbohydrates not only in the branches but also in the stem, which may have been exploited more to the middle and the end of the growing season, leading to larger radial growth. In general, warmer temperatures increase the photosynthetic processes that are associated with light, although an increase in photosynthesis does not necessarily translate into an immediate increase in growth [9]. Physiological acclimation in plants is a reversible short-term adjustment in photosynthesis and respiration in response to changes in growth temperature occurring over relatively short time scales [32,33]. Our results exemplify how the growth of the shrub species $P$. spinosa is able to respond to a short-term temperature change, likely reflecting physiological acclimation.

The warm condition in springtime advanced the timing of bud burst, and also shortened the duration of the phenophase. A similar result was obtained in a Frangula alnus Mill. warming experiment where cuttings advanced their bud burst and shortened the process of leafing out in a higher temperature environment [34]. An opposite reaction was observed in a similar warming experiment with Fagus sylvatica L. seedlings that showed an advancement of the onset of bud burst in the warm condition, though the duration of the leafing out was prolonged in this case [35]. As the warming of the F. sylvatica seedlings reduced both height and radial growth, indicating the development of thermal stress in the plants, our results denote warming as a growth stimulus for P. spinosa. This may suggest that changes in the duration of the leafing out process, rather than changes in the onset, could be responsible for the difference between stimulation versus retardation of growth upon warming under non-limiting water conditions. All warm conditions in our experiment (spring, summer/autumn, or both) resulted in delayed leaf senescence in the year of the treatments (2018), corroborated by a higher relative chlorophyll content in August of 2018. Warming has already been suggested to enhance the biosynthesis of chlorophyll in several tree species [36]. However, an elevated chlorophyll biosynthesis did not concur with a higher net photosynthetic rate in several temperate tree species upon warming [37]. Furthermore, the summer/autumn warming ("cold-warm" and "warmwarm") enlarged the duration of the leaf senescence process. In contrast to our results, dissection of bud set data in poplar led to the suggestion that for a given onset of bud set in poplar, the duration of the process is hastened in a warmer environment and prolonged in a colder environment [38]. Although photoperiod plays an important role in the bud set process of poplar [38], it may be less decisive in P. spinosa, allowing warmer autumnal temperatures for P. spinosa to slow down chlorophyll breakdown and leaf senescence, and longer photosynthetic activity. Only a relatively minor carry-over effect of the "cold-warm" condition, with a slightly delayed bud burst, was observed in the spring of 2019. This small effect is in line with a study on field-grown Betula pendula Roth and Betula pubescens Ehrh., where a mean September temperature of $14{ }^{\circ} \mathrm{C}$, compared with the historical mean of $9{ }^{\circ} \mathrm{C}$, delayed bud burst in the following spring [39]. No effect of the temperature treatments was detected anymore on the leaf senescence of 2019 and the bud burst of 2020 in our experiment. Altogether, the phenological response on the temperature treatments was only strong in the year of the temperature changes with little carry-over effects, whereas the effect on growth was only detectable in the following year.

\subsection{Differentiation among Provenances in the Common Garden Environment}

In terms of minimum and maximum climatic temperatures at the origin of the three studied provenances, the local Belgian provenance was adapted to the warmest climate (Figure 1). Although the origin of the Spanish Alpine provenance is located at a lower latitude than the Belgian provenance, the higher elevation causes a harsher growth environment. This is reflected by the observed growth patterns. The lower growth (less height and height increment, less diameter and diameter increment) of the non-local provenances (Spanish and Swedish) can be interpreted as a disadvantage for the non-local provenances in the common garden setting, corroborating the general statement that provenances originating from warmer 
areas (lower latitudes and/or lower elevation) usually have faster growth than those from cooler areas $[29,40]$.

The major cues driving phenology in temperate trees are temperature (including winter chilling and spring forcing) and photoperiod. They generally co-vary and interact, making plant responses complex and nonlinear [41]. In our experiment, the timing of bud burst and leaf senescence in the Spanish Alpine provenance was relatively close or similar to the local Belgian provenance, whereas for the Swedish provenance bud burst and leaf senescence were always delayed and advanced, respectively, possibly expressing adaptation to a shorter growing season. As the climate temperatures at the origin of the Spanish Alpine provenance are similar or cooler than the Belgian and the Swedish provenances, this corroborates the general knowledge that the provenances are not adapted to the mean environmental temperatures. Some other factors such as the photoperiod [42] may interplay and differences in required chilling and required growing degree days to bud break $[43,44]$. Moreover, a higher plastic response to the common garden environment for the Spanish provenance in comparison to the Swedish provenance could add to the variation in the timing of the phenophases. Plasticity in temperature responses was also observed in a previous study comparing the phenology of tree populations originating from different altitudes in a mountainous area that were brought together in provenance trials at the different altitudes [45].

Finally, larger plants had a shorter growing season in our experiment (later timing of bud burst and earlier timing of leaf senescence). This seems contradictory as a longer growing season is associated with better growth. However, the length of the growing season proved more important for the rate of growth than the summer temperatures [29]. As smaller plants in our experiment most likely experienced more shade cast by taller plants, this finding can be related to the variability in the phenology of sunlit versus shade leaves. Buds in beech that were formed in the shade sprouted earlier than those that were formed in full daylight. The shade buds had thinner and less tightly closed scale coverings and were therefore suggested to be more sensitive to external stimuli promoting the onset of bud burst [29].

\section{Conclusions}

Our results demonstrate that seedlings from the shrub species $P$. spinosa respond to elevated temperatures with immediate phenological adjustments. Warming extended the growing season with an earlier bud burst and a later leaf senescence. Still, the growth responses were retarded and only visible after one year. In addition, growth responses depended on the time in the growing season when the temperature was elevated. Interestingly, we observed that spring warming enhanced more height growth in the following year, whereas summer/autumn warming enhanced more radial growth in the following year.

Supplementary Materials: The following are available online at https:/ /www.mdpi.com/article/10 $.3390 / \mathrm{f13010023/s1}$, Figure S1: Bar plot of the modelled seedling height (a) and stem diameter (b) at the end of 2017, with standard error, for the three provenances in the common garden. Figure S2: Mean and standard deviation of the height increments and diameter increments of the P. spinosa seedlings in 2018, 2019, and 2020, according to the provenance. Table S1: Test statistics for the response variables plant height and stem diameter in 2017. The Belgian provenance is the standard to which the Spanish and Swedish provenances are compared to, Table S2. Test statistics for the response variables height increment and diameter increment in 2018, 2019 and 2020. The Belgian provenance is the standard to which the Spanish and Swedish provenances are compared to. The Tcold-cold condition of the temperature treatments in 2018 is the standard to which the other three conditions are compared to (Tcold-warm, Twarm-cold, and Twarm-warm), Table S3. Test statistics for the response variable bud burst during the spring temperature treatment in 2018. The Belgian provenance is the standard to which the Spanish and Swedish provenances are compared to. The Tcold condition of the temperature treatment in the spring of 2018 is the standard to which the other condition Twarm is compared to. H1 is the plant height at the end of 2017. D is the day. Table S4. Test statistics for the response variable leaf senescence during the summer/autumn temperature treatment 
in 2018. The Belgian provenance is the standard to which the Spanish and Swedish provenances are compared to. The Tcold-cold condition of the temperature treatments in 2018 (cold/warm in spring 2018-cold/warm in autumn 2018) is the standard to which the other three conditions are compared to (Tcold-warm, Twarm-cold, and Twarm-warm). H2 is the plant height at the end of 2018. D is day. Table S5. Test statistics for the response variable relative chlorophyll content on the 23rd of August 2018. The Belgian provenance is the standard to which the Spanish and Swedish provenances are compared to. The Tcold-cold condition of the temperature treatments in 2018 (cold/warm in spring 2018-cold/warm in autumn 2018) is the standard to which the other three conditions are compared to (Tcold-warm, Twarm-cold, and Twarm-warm). H2 is the plant height at the end of 2018. Table S6. Test statistics for the response variables bud burst and leaf senescence in 2019. The Belgian provenance is the standard to which the Spanish and Swedish provenances are compared to. The Tcold-cold condition of the temperature treatments in 2018 (cold/warm in spring 2018-cold/warm in autumn 2018) is the standard to which the other three conditions are compared to (Tcold-warm, Twarm-cold, and Twarm-warm). $\mathrm{H}$ is the plant height at the end of 2018 in the model of the response variable bud burst in 2019 and it is the plant height at the end of 2019 in the model of the response variable leaf senescence in 2019. D is day. Table S7. Test statistics for the response variables bud burst and leaf senescence in 2020. The Belgian provenance is the standard to which the Spanish and Swedish provenances are compared to. The Tcold-cold condition of the temperature treatments in 2018 (cold/warm in spring 2018-cold/warm in autumn 2018) is the standard to which the other three conditions are compared to (Tcold-warm, Twarm-cold, and Twarm-warm). $\mathrm{H}$ is the plant height at the end of 2019 in the model of the response variable bud burst in 2020 and it is the plant height at the end of 2020 in the model of the response variable leaf senescence in 2020. Table S8. Data. plantID: unique plant identity code, region: region of origin with S: Spain, V: Belgium and Z: Sweden, mpl: unique identity code for every mother plant from which seed was collected, treat1: treatment in the spring of 2018, treat2: combination of treatment in the spring of 2018 and summer/autumn 2018, headings of phenological scores consist of the phenophase abbreviation with bb: bud burst and se: leaf senescence, followed by the actual date of observation, h17 until h20: heights of the plants in 2017 until 2020, d17 until d20: diameters of the plants in 2017 until 2020, hinc18 till hinc20: height increments in 2018 until 2020, dinc18 until dinc20: diameter increments in 2018 until 2020, cc23aug18: relative chlorophyll content on this date.

Author Contributions: K.V.M., J.M.M. and E.N.P. conceptualized the presented research; methodology, K.V.M., J.M.M., S.M., E.N.P. and A.T.; data collection in terms of measurements and observations were carried out by J.M.M., S.M. and N.V.d.S.; K.V.M., J.M.M. and N.V.d.S. validated the data; statistical analysis was performed by K.V.M., J.M.M. and N.V.d.S.; K.V.M. and A.T. prepared the draft manuscript; K.V.M., A.T., E.N.P. and J.M.M. carried out the editing and reviewing of the manuscript. All authors have read and agreed to the published version of the manuscript.

Funding: This research received no external funding.

Institutional Review Board Statement: Not applicable.

Informed Consent Statement: Not applicable.

Data Availability Statement: The data are available as Table S8 in the Supplementary Materials.

Acknowledgments: We are most grateful to Jörg Brunet for the collection of berries in the south of Sweden.

Conflicts of Interest: The authors declare no conflict of interest.

\section{References}

1. Mohr, H.; Schopfer, P. Plant. Physiology; Springer: Berlin/Heidelberg, Germany, 1995; p. 629.

2. Han, S.; Chung, H.; Noh, N.J.; Lee, S.J.; Jo, W.; Yoon, T.K.; Yi, K.; Park, C.W.; Ko, S.; Son, Y. Effect of open-field experimental warming on the leaf phenology of oriental oak (Quercus variabilis) seedlings. J. Plant Ecol. 2014, 7, 559-566. [CrossRef]

3. Chung, H.; Muraoka, H.; Nakamura, M.; Han, S.; Muller, O.; Son, Y. Experimental warming studies on tree species and forest ecosystems: A literature review. J. Plant Res. 2013, 126, 447-460. [CrossRef]

4. Peltola, H.; Kilpelainen, A.; Kellomaki, S. Diameter growth of Scots pine (Pinus sylvestris) trees grown at elevated temperature and carbon dioxide concentration under boreal conditions. Tree Physiol. 2002, 22, 963-972. [CrossRef] [PubMed]

5. Nakamura, M.; Muller, O.; Tayanagi, S.; Nakaji, T.; Hiura, T. Experimental branch warming alters tall tree leaf phenology and acorn production. Agr. For. Meteorol. 2010, 150, 1026-1029. [CrossRef] 
6. Chen, L.; Huang, J.G.; Ma, Q.Q.; Hanninen, H.; Tremblay, F.; Bergeron, Y. Long-term changes in the impacts of global warming on leaf phenology of four temperate tree species. Glob. Chang. Biol. 2019, 25, 997-1004. [CrossRef]

7. Penuelas, J.; Rutishauser, T.; Filella, I. Ecology. Phenology feedbacks on climate change. Science 2009, 324, 887-888. [CrossRef] [PubMed]

8. Polgar, C.A.; Primack, R.B. Leaf-out phenology of temperate woody plants: From trees to ecosystems. New Phytol. 2011, 191, 926-941. [CrossRef]

9. Saxe, H.; Cannell, M.G.R.; Johnsen, B.; Ryan, M.G.; Vourlitis, G. Tree and forest functioning in response to global warming. New Phytol. 2001, 149, 369-399. [CrossRef]

10. Way, D.A.; Oren, R. Differential responses to changes in growth temperature between trees from different functional groups and biomes: A review and synthesis of data. Tree Physiol. 2010, 30, 669-688. [CrossRef]

11. Arend, M.; Brem, A.; Kuster, T.M.; Gunthardt-Goerg, M.S. Seasonal photosynthetic responses of European oaks to drought and elevated daytime temperature. Plant Biol. 2013, 15, 169-176. [CrossRef]

12. Sendall, K.M.; Reich, P.B.; Zhao, C.M.; Hou, J.H.; Wei, X.R.; Stefanski, A.; Rice, K.; Rich, R.L.; Montgomery, R.A. Acclimation of photosynthetic temperature optima of temperate and boreal tree species in response to experimental forest warming. Glob. Chang. Biol. 2015, 21, 1342-1357. [CrossRef]

13. Yamaguchi, D.P.; Nakaji, T.; Hiura, T.; Hikosaka, K. Effects of seasonal change and experimental warming on the temperature dependence of photosynthesis in the canopy leaves of Quercus serrata. Tree Physiol. 2016, 36, 1283-1295. [CrossRef]

14. Han, S.; Lee, S.J.; Yoon, T.K.; Han, S.H.; Lee, J.; Kim, S.; Hwang, J.; Cho, M.S.; Son, Y. Species-specific growth and photosynthetic responses of first-year seedlings of four coniferous species to open-field experimental warming. Turk. J. Agric. For. 2015, 39, 342-349. [CrossRef]

15. Noh, N.J.; Lee, S.J.; Jo, W.; Han, S.; Yoon, T.K.; Chung, H.; Muraoka, H.; Son, Y. Effects of experimental warming on soil respiration and biomass in Quercus variabilis Blume and Pinus densiflora Sieb. et Zucc. seedlings. Ann. Sci. 2016, 73, 533-545. [CrossRef]

16. Wertin, T.M.; McGuire, M.A.; Teskey, R.O. Higher growth temperatures decreased net carbon assimilation and biomass accumulation of northern red oak seedlings near the southern limit of the species range. Tree Physiol. 2011, 31, 1277-1288. [CrossRef] [PubMed]

17. Reich, P.B.; Sendall, K.M.; Rice, K.; Rich, R.L.; Stefanski, A.; Hobbie, S.E.; Montgomery, R.A. Geographic range predicts photosynthetic and growth response to warming in co-occurring tree species. Nat. Clim. Chang. 2015, 5, 148-152. [CrossRef]

18. Woldring, H. On the origin of plums: A study of sloe, damson, cherry plum, domestic plums and their intermediates. Palaeohistoria 2000, 39-40, 535-562.

19. Körber-Grohne, U. Pflaumen, Kirschpflaumen, Schlehen: Heutige Pflanzen und ihre Geschichte seit der Frühzeit; Konrad Theiss Verlag $\mathrm{GmbH}$ : Stuttgart, Germany, 1996.

20. Vander Mijnsbrugge, K.; Depypere, L.; Michiels, B.; De Cuyper, B. Genetic and temporal plastic variation in bud burst, bud set and flower opening responses of local versus non-local provenances of Prunus spinosa in a provenance trial. Basic Appl. Ecol. 2016, 17, 262-272. [CrossRef]

21. Vander Mijnsbrugge, K.; Turcsán, A.; Depypere, L.; Steenackers, M. Variance, Genetic Control, and Spatial Phenotypic Plasticity of Morphological and Phenological Traits in Prunus spinosa and Its Large Fruited Forms (P. $\times$ fruticans). Front. Plant Sci. 2016, 7, 1641. [CrossRef]

22. Cosmulescu, S.; Gavrila Calusaru, F. Influence of temperature on blackthorn (Prunus spinosa L.) phenophases in spring season. J. Agric. Meteorol. 2020, 76, 53-57. [CrossRef]

23. Fick, S.E.; Hijmans, R.J. WorldClim 2: New 1-km spatial resolution climate surfaces for global land areas. Int. J. Clim. 2017, 37, 4302-4315. [CrossRef]

24. NOAA Solar Calculator. Available online: https://gml.noaa.gov/ (accessed on 1 September 2021).

25. Parry, C.; Blonquist, J.M.; Bugbee, B. In situ measurement of leaf chlorophyll concentration: Analysis of the optical/absolute relationship. Plant Cell Environ. 2014, 37, 2508-2520. [CrossRef] [PubMed]

26. R_Core_Team. R: A Language and Environment for Statistical Computing; R Foundation for Statistical Computing: Vienna, Austria, 2019.

27. Bates, D.; Machler, M.; Bolker, B.M.; Walker, S.C. Fitting Linear Mixed-Effects Models Using lme4. J. Stat. Softw. 2015, 67, 1-48. [CrossRef]

28. Christensen, R.H.B. Ordinal: Regression Models for Ordinal Data. R Package Version 2015.6-28. Available online: http: / / www.cran.r-project.org/package=ordinal/ (accessed on 9 November 2019).

29. Büsgen, M.; Münch, E.; Thomson, T. The Structure and Life of Forest Trees; Chapman and Hall: London, UK, 1929.

30. Di Iorio, A.; Giacomuzzi, V.; Chiatante, D. Acclimation of fine root respiration to soil warming involves starch deposition in very fine and fine roots: A case study in Fagus sylvatica saplings. Physiol. Plant 2016, 156, 294-310. [CrossRef]

31. Furze, M.E.; Huggett, B.A.; Aubrecht, D.M.; Stolz, C.D.; Carbone, M.S.; Richardson, A.D. Whole-tree nonstructural carbohydrate storage and seasonal dynamics in five temperate species. New Phytol. 2019, 221, 1466-1477. [CrossRef]

32. Aspinwall, M.J.; Vårhammar, A.; Blackman, C.J.; Tjoelker, M.G.; Ahrens, C.; Byrne, M.; Tissue, D.T.; Rymer, P.D. Adaptation and acclimation both influence photosynthetic and respiratory temperature responses in Corymbia calophylla. Tree Physiol. 2017, 37, 1095-1112. [CrossRef] [PubMed]

33. Way, D.A.; Yamori, W. Thermal acclimation of photosynthesis: On the importance of adjusting our definitions and accounting for thermal acclimation of respiration. Photosynth. Res. 2014, 119, 89-100. [CrossRef] 
34. Vander Mijnsbrugge, K.; Turcsan, A.; Michiels, B. Population differentiation and phenotypic plasticity in temperature response of bud burst in Frangula alnus provenances of different latitude. Plant Syst. Evol. 2016, 302, 257-264. [CrossRef]

35. Vander Mijnsbrugge, K.; Malanguis, J.M.; Moreels, S.; Lauwers, A.; Thomaes, A.; De Keersmaeker, L.; Vandekerkhove, K. Growth Recovery and Phenological Responses of Juvenile Beech (Fagus sylvatica L.) Exposed to Spring Warming and Late Spring Frost. Forests 2021, 12, 1604. [CrossRef]

36. An, J.; Han, S.; Chang, H.; Park, M.J.; Kim, S.; Hwang, J.; Cho, M.S.; Chung, H.; Son, Y. Physiological and growth responses to experimental warming in first-year seedlings of deciduous tree species. Turk. J. Agric. For. 2017, 41, 175-182. [CrossRef]

37. Prieto, I.; Querejeta, J.I. Simulated climate change decreases nutrient resorption from senescing leaves. Glob. Chang. Biol. 2020, 26, 1795-1807. [CrossRef]

38. Rohde, A.; Bastien, C.; Boerjan, W. Temperature signals contribute to the timing of photoperiodic growth cessation and bud set in poplar. Tree Physiol. 2011, 31, 472-482. [CrossRef] [PubMed]

39. Heide, O.M. High autumn temperature delays spring bud burst in boreal trees, counterbalancing the effect of climatic warming Tree Physiol. 2003, 23, 931-936. [CrossRef] [PubMed]

40. Teskey, R.; Wertin, T.; Bauweraerts, I.; Ameye, M.; McGuire, M.A.; Steppe, K. Responses of tree species to heat waves and extreme heat events. Plant Cell Environ. 2015, 38, 1699-1712. [CrossRef] [PubMed]

41. Flynn, D.F.B.; Wolkovich, E.M. Temperature and photoperiod drive spring phenology across all species in a temperate forest community. N. Phytol. 2018, 219, 1353-1362. [CrossRef]

42. Basler, D.; Korner, C. Photoperiod and temperature responses of bud swelling and bud burst in four temperate forest tree species. Tree Physiol. 2014, 34, 377-388. [CrossRef]

43. Thibault, E.; Soolanayakanahally, R.; Keller, S.R. Latitudinal clines in bud flush phenology reflect genetic variation in chilling requirements in balsam poplar, Populus balsamifera. Am. J. Bot. 2020, 107, 1597-1605. [CrossRef]

44. Baumgarten, F.; Zohner, C.M.; Gessler, A.; Vitasse, Y. Chilled to be forced: The best dose to wake up buds from winter dormancy. N. Phytol. 2021, 230, 1366-1377. [CrossRef]

45. Vitasse, Y.; Hoch, G.; Randin, C.F.; Lenz, A.; Kollas, C.; Scheepens, J.F.; Körner, C. Elevational adaptation and plasticity in seedling phenology of temperate deciduous tree species. Oecologia 2013, 171, 663-678. [CrossRef] [PubMed] 